\title{
Proceeding
}

Supplementary Issue: Autumn Conferences of Sports Science. Costa Blanca Sports Science Events, 18-19 December 2020. Alicante, Spain.

\section{Propulsive strength training in wheelchair tennis to improve service response}

\author{
MARIA SALIERNO1 ${ }^{4}$, GIOVANNI ESPOSITO', RICCARDO IZZO², SIMONA FATTORE ${ }^{3}$, TIZIANA \\ D'ISANTO3
}

${ }^{1}$ Department of Human, Philosophical and Education Sciences, University of Salerno, Italy

${ }^{2}$ Department of Biological Sciences, University of Urbino, Italy

3University of Salerno, Italy

\begin{abstract}
In wheelchair tennis, the biomechanical-bioenergetic quantitative aspects involved are the fast force and maximum isometric propulsion force of the race medium. The problem encountered is to improve the propulsion force of the race medium, therefore the thrust force, to increase the strength of the upper limbs in the response to the service. The aim of the study is to verify the effects of a training with upper limb overloads on sports performance, in particular the response to the service. A sample of 30 paraplegic athletes, of an average age of 25 years, with a D8-D12 back injury, of the Open category, has been recruited. Athletes have been training with upper body overloads for 2 months with a frequency of 2 times a week. The $20 \mathrm{~m}$ sprint test was executed after and before the two months. The T-test for dependent samples was used to detect the difference between the two groups $(p<.05)$. Training with upper limb overloads showed a significant improvement $(p<.05)$ of $42 \%$ in service response. According to the results, athletes from an average initial performance level of 5.2 have moved to an average level of 4.82, which corresponds to an almost excellent level. Overload training has proven effective in increasing fast strength in response to the technical gesture of the opponent's service.
\end{abstract}

Keywords: Driving force; Wheelchair tennis; Training.

Cite this article as:

Salierno, M., Esposito, G., Izzo, R., Fattore, S., \& D'Isanto, T. (2021). Propulsive strength training in wheelchair tennis to improve service response. Journal of Human Sport and Exercise, 16(2proc), S726-S734. doi:https://doi.org/10.14198/jhse.2021.16.Proc2.58

Corresponding author. Department of Human, Philosophical and Education Sciences, University of Salerno, Italy.

E-mail: m.salierno3@studenti.unisa.it

Abstract submitted to: Autumn Conferences of Sports Science. Costa Blanca Sports Science Events, 18-19 December 2020. Alicante, Spain.

JOURNAL OF HUMAN SPORT \& EXERCISE ISSN 1988-5202

(c) Faculty of Education. University of Alicante

doi:10.14198/jhse.2021.16.Proc2.58

S726 | 2021| Proc2 | VOLUME 16

C 2021 University of Alicante 


\section{INTRODUCTION}

Wheelchair tennis is a discipline with many similarities to classic tennis, as the rules are very similar, as are the technical-tactical components (Santopietro et al., 2020). In wheelchair tennis, only two Paralympic categories are distinguished: Open category in which all those with a lower limb disability can compete (inside itis divided into men, women and Junior), and Quad category, reserved for those who in addition to having a disability in the lower limbs, have one also to the upper limbs (has no gender differentiation) (Mason et al., 2010). Each of these categories can be played in both single and double. Tennis being a sport of situation, it is characterized by the presence of variable movements to adapt to the surrounding environment (Raiola, 2019). Depending on the energy mechanism used by the muscles, tennis is configured as a mixed activity sport (Di Palma et al., 2016). This adapted sport involves the aerobic system along with short bouts of high intensity intermittent activity (Latorella et al., 2020). This intermittent nature of the game, with regular rest times allowed results in the actual playing time being approximately $15-20 \%$ of the total time; this is equivalent to a ratio of play to rest time. The game time is represented by the duration of the exchange, which typically lasts between 4 and 10 seconds. Performance in wheelchair sports is not only based on adequate physical fitness, but also on specific skills, experience and technical competence (Raiola et al., 2018). The athlete's interaction with the wheelchair must be considered, as this determines the propulsion of the latter and the sporting movements required within the competition. The movement dynamics of wheelchair tennis are specifically related to the push of the wheelchair while holding a tennis racket (D'Elia et al., 2020). This study highlights the complexity of muscle-powered wheelchair sport, due to the long learning of the technical skills necessary for the manoeuvrability of the race medium, characterized by aerobic moments alternating with anaerobic ones in which the actions last a few minutes or follow each other quickly. Since a match lasts about $60-80$ minutes and tennis is an alternate aerobic-anaerobic activity, the typical average heart rate for a match ranges from $65-75 \%$ (120 -140 bpm) of the maximum heart rate and an estimate of VO2max between 50 and $68 \%$ (Coutts, 1990). It is important to have a good level of overall strength on which to build good agility and a good expression of fast strength and explosive force. Since tennis is a sport that needs great speed and rapidity of gestures, with combinations of techniques quickly adapted to the purpose, it develops different forms of power to face the variables of the external environment to achieve the goal. Cardiorespiratory resistance capacity, medium intensity and prolonged for an average or long time (Jones et al., 1989). The biomechanical-bioenergetic quantitative aspects involved in wheelchair tennis are the fast force and maximum isometric propulsion force of the race medium (Altavilla, 2019). The complexity of muscle-traction wheelchair sports, including Wheelchair Tennis, is due both to the long learning of the technical skills necessary for the manoeuvrability of the racing vehicle and to the increase in specific muscle strength essential for the speed of the game of offensive actions (Cascone et al., 2019). Compared to the technical differences between the two sports, in wheelchair tennis a single grip is used, that is the western forehand, while the two-handed grip used, on the other hand, in "tennis for all" is less used for the backhand and the forehand (Mujika, Padilla, 2001). Tennis, as a situational sport, is characterized by a time of rapid reaction to constantly changing external stimuli. This sport provides for an optimal adaptation to the contingent technicaltactical situation in order to disorganize as much as possible the opponent's technique while keeping its own very effective (Goosey-Tolfrey \& Moss, 2002). It is necessary to maintain an optimal technique regardless of changing environmental situations. Among the technical-tactical gestures that allow to maintain the mastery of the point, used both in tennis for everyone and in wheelchair tennis, is the early shot especially in response to the service of the opponent (Conti et al., 2019). Unlike in non-disabled tennis where shots are also used on the fly (voleé by right, reverse voleé and smash) these in tennis for the non-disabled are not used. The difficulty in making a shot on the fly is that sitting in a wheelchair involves longer time to get near the net. The torsional action of the trunk and shoulders that is carried out in the preparation phase of the forehand is limited, therefore the players will be able to accumulate energy in less quantity (Altavilla et al., 2015). This 
will also affect the speed of impact and the production of power (Graves et al., 1988). When a wheelchair tennis player plays with or against a non-disabled tennis player in singles or doubles, wheelchair tennis rules will be applied to the wheelchair player while tennis rules will apply to the non-disabled player (Esposito et al., 2020). The rules of the game are the same with the only difference that the disabled player will be granted a double bounce of the ball, while the disabled tennis player is only allowed one rebound. The problem encountered in wheelchair tennis players is a limitation in the propulsion force of the wheelchair, therefore the thrust force, necessary to increase the strength of the upper limbs in the response to the service (Grant et al., 1999). Vehicular propulsion refers to the thrust transmitted to the wheelchair, sufficient to cause and maintain its movement (D'lsanto et al., 2019). A propulsion system, like the wheelchair, consists of a source of mechanical power, and a propeller (means of converting power into this propulsive force). Propulsion systems, in the case of wheelchair tennis, use muscles as a power source and the upper limbs as propellers (Di Domenico, 2020). A technological system uses muscle work to power a mechanical propulsion device.

\section{Aim of the study}

The aim of the study is to verify the effects of a training with upper limb overloads on sports performance after two months, in particular, evaluate any positive effects found in the response to the service.

\section{MATERIALS AND METHODS}

\section{Study participants}

In this study a sample of 30 paraplegic athletes with a D8-D12 back injury of an average age of 25 years, of the Open category, has been recruited. Experimental procedures, discomforts, and benefits were fully explained to all boys and parents/guardians prior to participation. Signed informative consent forms were provided by subjects and/or legal guardians. The substantial number and the significant representation of the sample means that it can be subject to professional discussion as well as scientific discussion.

\section{Training protocol}

Given that wheelchair players need a greater propulsion force and therefore a greater thrust of the competition vehicle, it was considered to carry out a training protocol with overloads of the upper limbs to be carried out 2 times a week and for 2 months on a group of 30 paraplegic athletes of the Open category. To verify the effects of training on sports performance, in particular the response to serve, the athletes carried out the Sprint test on $20 \mathrm{~m}$ with data acquisition both before and at the end of the two months of specific training. The Sprint-test has been chosen, since it allows to evaluate the reaction phase in a short time, and therefore to respond quickly to an external stimulus, such as the sound stimulus in the sprint test, pushing the wheelchair forward. This will allow to evaluate the player's reaction times in returning the opponent's serve. Moreover at least of 20 -meters sprint is minimum requirement of the tennis playing to reach the ball successfully. We therefore want to evaluate the technical-sporting improvement of the response to the service through the acquisition of input and output data of the Sprint test on $20 \mathrm{~m}$, detecting the difference of the two averages before and after training. The test was adapted to wheelchair athletes. A 20-meter long stretch of path was measured and was bordered with special stakes or cones. After an adequate warm-up, the athlete, starting from a standstill to the starting blocks, travels 20 meters in the shortest possible time. The athlete, after recovering the effort, repeats the test 2 more times. The assistant wrote down the travel time of the three tests. The lower time will be used in the final evaluation. The travel time will be determined by the set of two factors:

- Reaction phase: whose physiological limit is the passage of the stimulus into the nerve network and the formation of the efferent signal (simple reaction). 
- Acceleration phase: transition from speed 0 to maximum speed. It is the most force-sensitive phase because it takes place against high resistances.

After that, athletes have been training with upper body overloads for 2 months with a frequency of 2 times a week. As shown in Table 1, the training schedule provided for the execution of six types of exercises, each of which included three series of twenty repetitions. An adequate recovery time was expected between one series and another. The first exercise involved a rotation of the shoulders as an activation, consisting in the rotational movement of the outstretched arms, around the shoulder joint, from the front to the back through the top, involving the scapulo-humeral joint. The second exercise involved lifting the barbell on a flat bench. The exercise focuses on developing the pectoralis major muscle and as well as other complementary muscles including the anterior deltoids, anterior serratus muscles, coracobrachialis muscle and triceps. The person performing the exercise lowers the weight to chest level, and then pushes it until the elbow reaches full extension. During the execution of the exercise the shoulder blades remain adducted so as to preserve the health of the shoulder and so as to have a simultaneous stretching of the pectoral bundles. The third exercise, which involved the Let machine forward, works mainly on the great dorsal muscle, involving both the posterior deltoid and the central region of the trapezius as secondary muscles. Both the forearms and the biceps are involved as accessory muscles. Pull the bar down until it touches the upper chest. The elbows are turned outwards. After a moment of muscle contraction, return to the starting position. The fourth exercise involved lateral raises with dumbbells, an exercise with weights aimed mainly at stimulating the lateral head of the deltoid muscle. The start of the movement involves the arms at the sides and not in front of the body, while the dumbbells are held in a prone position, that is, during the execution the palms look downwards. During the abduction movement of the arms, the elbows are slightly flexed and locked, so they do not vary their length and are not mobilized during execution. The joint block of the elbow makes this exercise monoarticular or isolation, meaning that the only mobile joint during movement is that of the shoulder. The fifth exercise involved the two dumbbell curl. It was necessary to flex the arms bringing the dumbbells to touch the shoulders. Controlling the return phase until the arms are straight down again is one of the fundamental exercises for the biceps, creating volume and muscle mass. Finally, the last exercise involved the extension to polyerculin involving, through the draft, the different muscle groups of the upper part of the body.

Table 1. Training protocol description.

\begin{tabular}{llccl}
\hline Number & Exercises & Series and Repetition & Recovery & Muscle Group \\
\hline 1 & Lateral rotation of Shoulder & $3 \times 20$ & $20 \mathrm{~s}$ & Bachelor-Humeral joint \\
2 & Flat barbell bench & $3 \times 20$ & $1 \mathrm{~m}$ & Large bib \\
3 & Let machine ahead & $3 \times 20$ & $1 \mathrm{~m}$ & Large dorsal \\
4 & Lateral raises & $3 \times 20$ & $1 \mathrm{~m}$ & Lateral deltoid \\
5 & Dumbbells Curl & $3 \times 20$ & $1 \mathrm{~m}$ & Brachial biceps \\
6 & Extensions to polyerculin & $3 \times 20$ & $1 \mathrm{~m}$ & Brachial triceps \\
\hline
\end{tabular}

At the end of the two months of training with overloads, the $20 \mathrm{~m}$-sprint $\mathrm{i}$ test was repeated, recording the time taken by the athlete in the wheelchair to complete the sprint from the appearance of the initial sound stimulus.

\section{Statistical analysis}

The data obtained from the execution of the tests showed a normal distribution and were presented as mean and standard deviation (SD). A t-test for independent samples was conducted to combine the results obtained from the tests before the start of the specific training mesocycle, and at the end of it, after five weeks. The ttest was selected as an analytical method to check for the presence or absence of a significant difference 
between two data series. The significant level was set at $p<.05$. Statistical analyzes were performed with IBM SPSS Statistics 23 software. In hypothesis $\mathrm{HO}$ it has been hypothesized that the averages of the two samples are the same while in the alternative hypothesis $\mathrm{H} 1$ a variation of the two averages has been hypothesized. By placing a significance level of $5 \%$, there is a probability of making mistakes 5 times out of 100 in accepting or rejecting a hypothesis.

\section{RESULTS}

Table 2. 20m-sprint test evaluation parameters.

\begin{tabular}{lcc}
\hline Evaluation & Male & Female \\
\hline Excellent & $<4.80$ & $<5.30$ \\
Good & $4.80-5.09$ & $5.30-5.59$ \\
Average & $5.10-5.29$ & $5.60-6.20$ \\
Poor & $5.30-5.60$ & $5.30-5.59$ \\
Insufficient & $>5.60$ & $>6.20$ \\
\hline
\end{tabular}

Table 3. Recruitment of sprint test inbound and outbound values.

\begin{tabular}{lcc}
\hline Athletes & Before the training period (sec) & After he training period (sec) \\
\hline Athlete 1 & 5.15 & 4.78 \\
Athlete 2 & 5.23 & 4.67 \\
Athlete 3 & 5.18 & 4.56 \\
Athlete 4 & 5.20 & 4.75 \\
Athlete 5 & 5.30 & 4.45 \\
Athlete 6 & 5.45 & 4.56 \\
Athlete 7 & 5.43 & 4.76 \\
Athlete 8 & 5.60 & 4.89 \\
Athlete 9 & 5.55 & 4.67 \\
Athlete 10 & 5.58 & 4.56 \\
Athlete 11 & 5.00 & 4.78 \\
Athlete 12 & 4.8 & 4.56 \\
Athlete 13 & 5.65 & 4.67 \\
Athlete 14 & 6.76 & 4.45 \\
Athlete 15 & 5.78 & 4.59 \\
Athlete 16 & 5.67 & 4.34 \\
Athlete 17 & 5.12 & 4.89 \\
Athlete 18 & 5.45 & 4.43 \\
Athlete 19 & 5.36 & 4.54 \\
Athlete 20 & 5.38 & 4.56 \\
Athlete 21 & 5.39 & 4.78 \\
Athlete 22 & 5.40 & 4.89 \\
Athlete 23 & 4.45 & 4.65 \\
Athlete 24 & 5.56 & 4.63 \\
Athlete 25 & 5.59 & 4.34 \\
Athlete 26 & 5.6 & 4.49 \\
Athlete 27 & 5.43 & 4.67 \\
Athlete 28 & 5.41 & 4.57 \\
Athlete 29 & 5.34 & 4.78 \\
\hline & S730 & \\
S2 & \\
\hline
\end{tabular}




\begin{tabular}{lcc}
\hline Athlete 30 & 5.22 & 4.35 \\
AverageSD & $5.40 \pm 0.37$ & $4.62 \pm 0.15$ \\
\hline
\end{tabular}

Table 5. Test $t$ for dependent samples.

\begin{tabular}{lcc}
\hline & Variable 1 & Variable 2 \\
\hline Mean & 5.397 & 4.6253 \\
Variance & 0.140048 & 0.02541 \\
Observation & 30 & 30 \\
Hypothesized Mean Difference & 0 & \\
$d f$ & 29 & \\
$t$ Stat & 9.6046 & \\
$p(T<=t)$ one-tail & $8.17 \mathrm{E}-11$ & \\
$T$ critical one tail & 1.6991 & \\
$p(T<=t)$ two-tail & $1.63 \mathrm{E}-10$ & \\
$T$ critical two-tail & 2.0452 & \\
\hline
\end{tabular}

\section{DISCUSSION}

The results detected by the T-test show that in relation to $29 \mathrm{gdl}$ and placing as a level of significance $\mathrm{a}=$ .05 , one has that acceptance region $-1.69 \leq x \leq 1.69$. So since the value of the stat $t=9.20$ does not fall within the range and belongs to the reject region, we can reject the hypothesis $(\mathrm{H} 0)$ that assumed an equal value of the two averages and we can accept the alternative hypothesis that assumed, instead, a variation of the two averages. Upper limb overload training showed a significant $(p<.05) 42 \%$ improvement in service response. According to the results, athletes from an average initial performance level of 5.4 went to an average level of 4.62 , which corresponds to a good level as can be seen from Table 2. Data on the difference between the two groups were recruited on the basis of the results of the $20 \mathrm{~m}$ sprint test. The dependent sample static test tool was used to detect the comparison between the two averages before and after training. The training protocol was deemed necessary to improve fast strength in response to serve. The increased strength of the upper limbs allowed the athletes to maneuver the competition vehicle with only one limb while the other was busy breathing the moving ball. Compared to the start of the study, the athletes developed an increase in reaction times in the opponent's offensive actions and there was also greater self-efficacy in the game's tactical actions. In a similar study of Rangarajan and Elumalai (2020) a wheelchair mobility training is specially invented for the wheelchair athletes since that wheelchair tennis game requires the fast movement with wheelchair to all over the playing area (Boccia et al., 2019). The study implies to access the 20-meter sprint with wheelchair the performance was assessed and computed from pre-test performance to post-test performance the $11.51 \%$ improvement was observed. The improvement was significant when compared to the $t$ - ratio obtained from the results of the study. It also inferred that the performance was better than compared to the control group. Wheelchair maneuvers may include propulsion, starting, stopping, and direction changes of the wheelchair, activities that require explosive strength and speed. The results of this study are also supported with results obtained from the study conducted by during Wheelchair Basketball practice, players perform bodily efforts to fast movements and quick direction changes, which requires power from the upper limbs (Gorgatti \& Bohme, 2002; D'Elia et al., 2020). Additionally, the movements of the training exercises in these sport are dribbling, passing and throwing the ball to the basket; thus, the strength of the upper limbs tends to be more required (Oudejans, Heubers, Ruitenbeek, \& Janssen, 2012). Thus, muscle strength and power are determinants and fundamental to success in this sport (Cardoso, 2011). Our data showed that explosive strength training improved sprint speed by $11.51 \%$ for a $20-\mathrm{m}$ distance. Our lower improvement in sprint speed than in the study by Turbanski and Schmidtbleicher (2010) may be related to a 
shorter training duration and intensity of training. The important factor of this positive results is based on the scientific reason behind the training protocol which includes the repeated movement which develops muscular strength and endurance of the upper extremity. The duration of the explosive strength training is unlikely to have resulted in muscle hypertrophy as in common with heavy resistance training (Haff et al., 2001; Hakkinen K., 1994; Hakkinen K. et al., 1985). The neural adaptations such as an increased motor unit synchronization and firing rate may have contributed to the improvement of speed. It is very likely that this development was the result of neural adaptations for a shorter duration of eight weeks.

\section{CONCLUSION}

The results obtained from the t-test were useful and consistent with the identified goal of detecting a difference in sprint test averages that demonstrated the effectiveness of training with upper body overloads to increase fast strength in response to the technical gesture of the opponent's service. In fact, the increase in the value of the sprint-test output average. Overload training has proven effective in increasing fast strength in response to the technical gesture of the opponent's service.

\section{REFERENCES}

Altavilla, G., Furino, F., Marika, D.P., Raiola, G. (2015). Physical skills, sport learning and socio-affective education [Fizičke vještine, sportsko učenje I društveno-afektivno obrazovanje], Sport Science, 8, pp. 44-46. Cited 42 times.

Altavilla, G. (2019). Monitoring training to adequate the teaching method in training: An interpretative concepts, Journal of Physical Education and Sport, 19, art. no. 258, pp. 1763-1766.

Boccia, S., Izzo, R., D'Elia, F., Fattore, S. (2019). A wheelchair by the overboard model: A technological instrument for disabled basketball players. Journal of Human Sport and Exercise, 14 (Proc4), pp. S1080-S1086. https://doi.org/10.14198/jhse.2019.14.Proc4.71

Cardoso, V. D. (2011). Rehabilitation of people with disabilities through adapted sport. Brazilian Journal of Sport Sciences, 2, 529-539.

Cascone, C., De Cesare, G.R., D'Elia, F. (2020). Physical education teacher training for disability, Journal of Human Sport and Exercise, 15, pp. S634-S644. https://doi.org/10.14198/jhse.2020.15.Proc3.16

Conti, L., Martinelli, M., Vago, P. "La Resilienza Nello Sport-Tennis e disabilità." (2019): 70-77. http://hdl.handle.net/10807/145535

Coutts D. K., Kinematics of sport Wheelchair propulsion. (1990). Journal Rehabilitation Research Development, 27, 1, 21-26. https://doi.org/10.1682/JRRD.1990.01.0021

D'Elia, F., Di Domenico, F., D'Isanto, T., Altavilla, G., Raiola, G. (2020). From biomechanics to motor learning, Acta Medica Mediterranea, 36 (5), pp. 3073-3078.

D'Elia, F., Rago, V., Ermidis, G., Raiola, G. (2020). Relationship between lower limb asymmetries and functional capacities in women in Basketball: A case study. Sport Science, 13 (1), pp. 90-95.

Di Domenico, F. (2020). From biomechanics to learning: Continuum for the theory of physical and sports education, Journal of Human Sport and Exercise, 15 (Proc2), pp. S268-S278. https://doi.org/10.14198/ihse.2020.15.Proc2.18

D'Isanto, T., D'Elia, F., Raiola, G., Altavilla, G. (2019). Assessment of sport performance: Theoretical aspects and practical indications. Sport Mont, 17 (1), pp. 79-82. https://doi.org/10.26773/smj.190214

Di Palma, D., Raiola, G., Tafuri, D. (2016). Disability and sport management: A systematic review of the literature, Journal of Physical Education and Sport, 16 (3), art. no. 125, pp. 785-793. 
Esposito, G., Ceruso, R., D'Elia, F., D'Isanto, T. (2020). Performance anxiety: How to play reliable and rational tennis by reducing mental pressure. Journal of Human Sport and Exercise, 15(2proc), S213S221. https://doi.org/10.14198//hse.2020.15.Proc2.12

Gorgatti, M., Bohme, M. (2002). Upper body power and agility in wheelchair basketball players. Journal of Brazilian Adapted Motor Activity Association, 7(1), 9-14.

Goosey-Tolfrey V. L., Moss A.D. (2002). Wheelchair Velocity of Tennis Players During Propulsion with and Without the Use of Racquets, Adapted Physical Activity Quarterly, 22, 291-301. https://doi.org/10.1123/apaq.22.3.291

Grant S., Aitchison T., Henderson E., Christie J., Zare S., Mcmurray J., Dargie H. (1999). A comparison of the reproducibility and the sensitivity to change of visual analogue scales, Borg scales, and Likert scales in normal subjects during submaximal exercise, Chest, 116, 5, 1208-1217. https://doi.org/10.1378/chest.116.5.1208

Graves J. E., Pollock M. L., Leggett S. H., Braith R. W., Carpenter D. M., Bishop L. E. (1988). Effect of Reduced Training Frequency on Muscular Strength, International Journal of Sport Medicine, 9, 5, 316- 319. https://doi.org/10.1055/s-2007-1025031

Haff G, Whitley A, Potteiger JA. (2001). Explosive exercises and sports performance. Strength Cond J.;23(3):13-20.

Hakkinen K. (1994). Neuromuscular adaptation during strength training, aging, detraining, and immobilization. Crit Rev Phys Rehab Med., 6:161-98.

Hakkinen K, Komi PV, Alen M. (1985). Effects of explosive type strength training on isometric force and relaxation time, electromyographic and muscle fibre characteristics of leg extensor muscles. Acta Physiol Scand.,125:587-600. https://doi.org/10.1111//.1748-1716.1985.tb07760.x

Jones D. A, Rutherford O. M., Parker D. F. (1989). Physiological changes in skeletal muscle as a result of strength training, Quarterly Journal of Experimental Physiology, 74, 3, 233-256. https://doi.org/10.1113/expphysiol.1989.sp003268

Latorella, V., Di Domenico, F., Altavilla, G. (2020). Neuromuscular adaptations to a motor skills training program for adults with intellectual disabilities. Journal of Human Sport and Exercise, 15 (Proc3), art. no. S676. https://doi.org/10.14198/ihse.2020.15.Proc3.20

Mason B. S., Porcellato L., van der Woude L. H., Goosey-Tolfrey V. L. (2010). A qualitative examination of wheelchair configuration for optimal mobility performance in wheelchair sports: a pilot study, Journal Rehabilitation Research Development, 42, 2, 141-149. https://doi.org/10.2340/16501977$\underline{0490}$

Mujika I., Padilla S. (2001). Muscular characteristics of detraining in humans, Medicine \& Science in Sport \& Exercise, 33, 8, 1297-1303. https://doi.org/10.1097/00005768-200108000-00009

Oudejans, R. R., Heubers, S., Ruitenbeek, J. R. J., \& Janssen, T. W. (2012). Training visual control in wheelchair basketball shooting. Research Quarterly for Exercise and Sport, 83(3), 464-469. https://doi.org/10.1080/02701367.2012.10599881

Raiola, G., D'elia, F., Altavilla, G. (2018). Physical activity and sports sciences between European Research Council and academic disciplines in Italy. Journal of Human Sport and Exercise, 13, pp. S283-S295. https://doi.org/10.14198/hse.2018.13.Proc2.13

Raiola, G. (2019). Comparison of exercise and sport sciences epistemology between european research council structure panel and Italian academic system. Sport Science, 12, pp. 112-120.

Santopietro, F., Fattore, S., Di Domenico, F., Sannicandro, I. (2020). Tennis and learning through the fit junior program: Observations and results for the didactics aim, Journal of Human Sport and Exercise, 15 (Proc3), pp. S619-S627. https://doi.org/10.14198/ihse.2020.15.Proc3.14 
Turbanski S., Schmidtbleicher D. (2010). Effects of heavy resistance training on strength and power in upper extremities in wheelchair athletes, Journal of Strength and Conditional Research, 24,1, 8-16. https://doi.org/10.1519/JSC.0b013e3181bdddda

\section{(c) $(1) \Theta$}

This work is licensed under a Attribution-NonCommercial-NoDerivatives 4.0 International (CC BY-NC-ND 4.0). 